\title{
Efeito residual de coberturas em pré-plantio no cultivo da mandioca em LATOSSOLO AMARELO Distrófico no Piauí
}

\section{Residual effect of Pre-planting Cover Crops on Cassava Cultivation in Oxisols in the State of Piauí, Brazil}

\author{
Mauro Sergio Teodoro \\ Empresa Brasileira de Pesquisa Agropecuária \\ E-mail: mauro-sergio.teodoro@embrapa.br \\ OrcID: https://orcid.org/0000-0002-0099-766X \\ Fernando Silva Araújo \\ Universidade Estadual do Piauí \\ E-mail: fernandoaraujo@phb.uespi.br \\ OrcID: https://orcid.org/0000-0003-1150-5867
}

Josué Rodrigues Barroso

Universidade Estadual do Piauí

E-mail: josuebarroso23@gmail.com

OrcID:https://orcid.org/0000-0001-5040-92549

Lucas de Oliveira Freitas

Universidade Estadual do Piauí

E-mail: lucasfreitasbarras@hotmail.com

OrcID: https://orcid.org/0000-0003-1971-2262

\begin{abstract}
Resumo: Na região semiárida, o cultivo da mandioca é praticado essencialmente por pequenos agricultores, cujos ciclos sucessivos na mesma área, podem levar ao esgotamento da fertilidade do solo. O uso de plantas de cobertura em pré-plantio é uma prática recomendada para melhoria das características físico-químicas do solo, todavia, seus efeitos sobre as características agronômicas da mandioca ainda são pouco estudados. O objetivo deste estudo foi avaliar o desenvolvimento e a produção da mandioca (Manihot esculenta), referente aos anos safras de 2014/15 e 2015/16, sob a biomassa seca das diferentes coberturas vegetais utilizadas em pré-plantio em LATOSSOLO AMARELO Distrófico psamítico, no litoral Piauiense.O delineamento empregado foi o inteiramente casualizado, com os tratamentos dispostos em fatorial $2 \times 3$, correspondendo a dois sistemas de manejo: roçado e roçado+incorporado; e três culturas de cobertura: vegetação espontânea, crotalária juncea e feijão-de-porco, com quatro repetições. Foram avaliados a produtividade, número de raízes por planta, massa média de raiz, diâmetro médio da haste, comprimento médio da raiz, massa verde de raízes, massa verde da parte aérea, massa total índice de colheita, além do aporte de biomassa seca resultante dos cortes das plantas de cobertura. A $C$. juncea apresentou a maior produção de biomassa seca. As coberturas vegetais utilizadas em pré-plantio como adubos verdes não influenciaram nas características agronômicas da mandioca na região do litoral Piauiese.
\end{abstract}

Palavras-chave: Adubos verdes. Crotalária juncea. Feijão-de-porco. Manihot esculenta.

Abstract: In the semi-arid region, small producers breed essentially cassava, whose successive cycles in the same area can result in the depletion of soil fertility. The use of cover crops in pre-planting is a recommended practice to enhance the physical and chemical characteristics of the soil. However, its effects on the cassava agronomic characteristics are still poorly studied. The objective of this study was to evaluate the development and production of cassava (Manihot esculenta) for the harvest years of 2014/15 and 2015/16, under the dry biomass of the different cover crops used in pre-planting in Oxisols on the coast of Piauí. The design applied was completely randomized with treatments arranged in a $2 \times 3$ factorial, corresponding to two management systems: mowing and mowing + incorporated; and three cover crops: spontaneous vegetation, Crotalaria juncea and jack bean, with four replications. We evaluated the yield, number of roots per plant, average root mass, average stem diameter, average root length, green root mass, green mass of the aerial part, total 
harvest index mass, plus the dry biomass contribution resulting from the cover crop cuts. $C$. juncea showed the highest production of dry biomass. The cover crops used in pre-planting such as green manure did not have any influence on the cassava agronomic characteristics on the coast of Piauí.

Keywords: Crotalaria juncea. Green manure. Jack beans. Manihot esculenta.

Data de recebimento: $13 / 03 / 2020$

Data de aprovação: 03/12/2020

DOI: https://doi.org/10.30612/agrarian.v14i52.11227

\section{Introdução}

A mandioca é um dos alimentos mais consumidos no mundo, destacando-se pela sua rusticidade e grande capacidade de adaptação a condições desfavoráveis de clima e solo, podendo ser utilizada para consumo humano, animal ou industrial.

De acordo com o último levantamento da Organização das Nações Unidas para a Alimentação e a Agricultura (FAO), a produção mundial de raiz de mandioca correspondeu a 277,81 milhões de toneladas no ano de 2018, estando o Brasil na quinta posição com uma produção de 17,6 milhões de toneladas (FAO, 2018). No Brasil, a Região Norte lidera a produção de mandioca com $38,5 \%$ da safra nacional, destacando-se como principal produtor, o estado do Pará, com 3,9 milhões de toneladas. As regiões Norte e Nordeste possuem juntas aproximadamente $58,54 \%$ da produção nacional de mandioca (t) em $69,3 \%$ das áreas cultivadas (ha). Entretanto, apresentam os menores índices de rendimento médio em $\mathrm{kg} / \mathrm{ha}$ de mandioca produzida, 15,19\% e 9,8\%, respectivamente (IBGE, 2019).

O Estado do Piauí é o sexto maior produtor de mandioca do Nordeste, com uma produtividade média de 9,65 $\mathrm{t} \mathrm{ha}^{-1}$, média anual em 2019 (IBGE, 2019). No estado, a cultura é considerada como responsável pela economia de subsistência para boa parte da população rural, sendo muito relevante quanto às relações sociais envolvendo produções familiares, comunitárias e/ou assalariadas, e ainda como alimento básico da população através da fabricação da farinha, que é realizada predominantemente de forma artesanal.

Na região centro norte do Piauí, são vários os aspectos que envolvem o cultivo da mandioca, como o cultivo da "roça no toco", praticado essencialmente por pequenos agricultores descapitalizados, e que consiste na derrubada e queima da vegetação existente na área, seguindo-se de um período de cultivo e, após o declínio da fertilidade do solo, por um período de pousio para restauração da fertilidade; o frequente aproveitamento de resíduos na alimentação animal; a falta de um sistema de produção definido para a cultura; e o cultivo em solos de baixa fertilidade natural, como no caso da Planície Litorânea (Araujo et al., 2019).

De acordo com Mehl, Sagrilo, Arzabe, (2010), a fragilidade dos locais de cultivo dificulta o plantio da mandioca nessa região, pois, há o predomínio de solos arenosos, com baixos teores de matéria orgânica. Além disso, o clima é caracterizado por altas temperaturas, longos períodos de seca e vento constante. Apesar das dificuldades, o solo da região está definitivamente incorporado ao processo produtivo da mandioca, cultura extremamente significativa na alimentação piauiense, além de exercer papel importante na geração de emprego e de renda.

Essa fragilidade é potencializada pela forma de preparo do solo, geralmente realizado com uma aração e duas gradagens quando há acesso ao implemento agrícola, ocasionando a degradação dos agregados e a compactação do solo, além da mineralização da matéria orgânica e diminuição da produtividade da cultura da mandioca (Devide, Castro, Valle, Feltran, Almeida, 2017). Melhorias no manejo do solo podem ser adquiridas com a adubação verde, que se configura como uma das alternativas que pode minimizar os impactos negativos causados pelos monocultivos no Semiárido nordestino.

Vários estudos têm demonstrado os efeitos benéficos das plantas de cobertura (adubos verdes) na manutenção e melhoria dos atributos físicos (Cardoso, Bento, Moreski, Gasparotto, 2014), químicos (Faria, Soares, Leão, 2004) e biológicos (Oliveira, Lima, Ambrósio, Bezerra Neto, Chaves, 2017) nas condições de semiárido. Entretanto, no Nordeste do Brasil, os sistemas de manejo devem priorizar a conservação do solo com o uso de coberturas vegetais ou seus resíduos, principalmente em regiões nas quais a proteção do solo contra as condições climáticas adversas, para muitas espécies, é um fator a ser observado (Giogongo, Salviano, Santana, Costa, Yuri, 2016). 
Os adubos verdes podem ser indicados para os solos da região dos Tabuleiros Litorâneos do Piauí (Teodoro, Castro, Magalhães, 2018), porém, segundo Guareschi \& Pereira (2015), para alcançar os benefícios supracitados, o manejo conservacionista precisa ser planejado e executado por anos consecutivos para benefícios duradouros.

O território da Planície Litorânea, mais especificamente o litoral Piauiense, constitui-se como um crescente pólo de produção orgânica no estado do Piauí. Neste sentido, pequenos e médios produtores descapitalizados, técnicos da extensão pública e privada, movimentos agroecológicos organizados, e consumidores são demandadores de tecnologias, como a adubação verde, apropriadas à produção orgânica. Entretanto, são escassos os trabalhos sobre adubação verde para a cultura da mandioca nesta região.

O objetivo deste trabalho foi avaliar o desenvolvimento e as características agronômicas da cultura da mandioca (Manihot esculenta Crantz) sob o aporte de resíduos vegetais de diferentes coberturas utilizadas em pré-plantio em LATOSSOLO AMARELO Distrófico psamítico na região do litoral Piauiense.

\section{Material e Métodos}

O experimento foi desenvolvido durante os anos safras de 2014/15 e 2015/16, na Embrapa MeioNorte/Unidade de Execução de Pesquisa de Parnaíba, coordenadas $03^{\circ} 05^{\prime} \mathrm{S}$ e $41^{\circ} 46^{\prime}$ ' W, e 46,8 m de altitude, em LATOSSOLO AMARELO Distrófico psamítico (Santos et al., 2018), textura média com relevo plano e suave ondulado.

O clima da região é do tipo Aw, com chuvas anuais entre $800 \mathrm{~mm}$ (longitude $42 \mathrm{~W}$, caracterizado como a região mais seca do clima Aw no Brasil) até $1.400 \mathrm{~mm}$ (longitude $46 \mathrm{~W}$ ), apresentando inverno seco e temperatura média superior a $26^{\circ} \mathrm{C}$ (Alvares, Stape, Sentelhas, Alves, Sparovek, 2014).

Foram coletadas dez amostras simples de solo em pontos diversos, de modo a obter-se uma maior representatividade da área experimental. Do material coletado e uniformizado, foi retirada uma amostra composta e conduzida ao Laboratório de Água e Solo da Embrapa Meio-Norte utilizou-se a metodologia de Raij et al. (2001) para as análises químicas (Tabela 1).

Tabela 1. Caracterização química do LATOSSOLO AMARELO Distrófico psamítico nas camadas de 0,0-0,10 e $0,10-0,20$ m de profundidade ${ }^{(1)}$.

\begin{tabular}{lcc}
\hline & Índices & \multicolumn{2}{c}{ Profundidade de amostragem $(\mathbf{m})$} \\
\cline { 2 - 3 } & $0,0-0,10$ & $0,10-0,20$ \\
\hline $\mathrm{pH}\left(\mathrm{H}_{2} \mathrm{O}\right)\left(\mathrm{em} \mathrm{água}^{-3}\right)$ & 6,35 & 6,43 \\
Fósforo $\left(\mathrm{mg} \mathrm{dm}^{-3}\right)$ & 75,86 & 38,96 \\
Potássio $\left(\mathrm{cmol}_{\mathrm{c}} \mathrm{dm}^{-3}\right)$ & 0,31 & 0,41 \\
Sódio $\left(\mathrm{cmol}_{\mathrm{c}} \mathrm{dm}^{-3}\right)$ & 0,09 & 0,09 \\
Cálcio $\left(\mathrm{cmol}_{\mathrm{c}} \mathrm{dm}^{-3}\right)$ & 6,59 & 3,04 \\
Magnésio $\left(\mathrm{cmol}_{\mathrm{c}} \mathrm{dm}^{-3}\right)$ & 1,63 & 0,84 \\
Alumínio $\left(\mathrm{cmol}_{\mathrm{c}} \mathrm{dm}^{-3}\right)$ & 0,05 & 0,01 \\
$\mathrm{H}+\mathrm{Al}\left(\mathrm{cmol}_{\mathrm{c}} \mathrm{dm}^{-3}\right)$ & 1,94 & 1,38 \\
Nitrogênio $\left(\mathrm{dag} \mathrm{kg}^{-1}\right)$ & 0,11 & 0,05 \\
MO $\left(\right.$ dag kg $\left.^{-1}\right)$ & 2,94 & 1,43 \\
$\mathrm{CTC}\left(\mathrm{cmol}_{\mathrm{c}} \mathrm{dm}^{-3}\right)$ & 3,92 & 4,09 \\
\hline
\end{tabular}

(1) Realizado no primeiro ano de cultivo. $\mathrm{pH}$ = Potencial hidrogeniônico; $\mathrm{P}$ = Fósforo; $\mathrm{K}$ = Potássio; $\mathrm{Na}$ = Sódio; $\mathrm{Ca}=\mathrm{Cálcio}$; $\mathrm{Mg}=$ Magnésio; Al = Alumínio; $\mathrm{H}+\mathrm{Al}$ = Acidez potencial; $\mathrm{N}$ = Nitrogênio; $\mathrm{MO}$ = Matéria Orgânica; CTC = Capacidade de troca catiônica.

Os dados de precipitação pluviométrica, referentes ao período de condução do experimento, foram registrados pela estação climatológica localizada no Campo Experimental da Embrapa Meio-Norte em Parnaíba. Durante o período de abril de 2014 a julho de 2016, períodos que correspondem ao início e o final do experimento, a média de precipitação pluvial foi de $75,3 \mathrm{~mm} / \mathrm{mês}$ (Figura 1). 


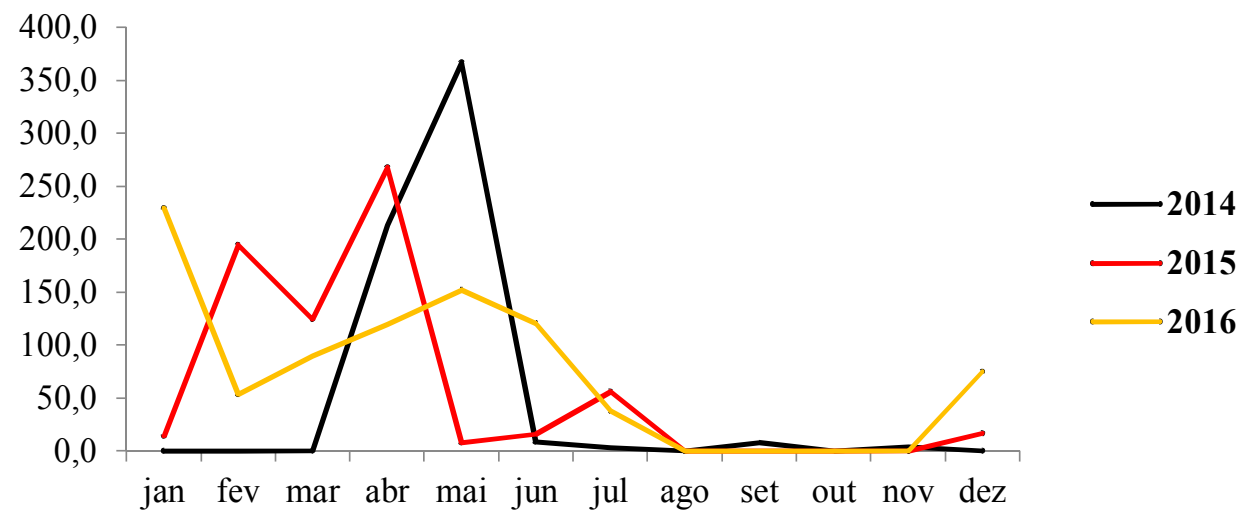

Figura 1. Médias de precipitação referentes ao período de execução do trabalho. Parnaíba-PI, 2016.

O delineamento experimental utilizado foi o inteiramente casualizado em esquema fatorial $2 \times 3$, onde foram avaliados dois sistemas de manejo em cultivo mínimo: roçado $(R)$ e roçado+incorporado $(R+I)$; e três culturas de cobertura: vegetação espontânea (VE), crotalária juncea (Crotalaria juncea) (CJ) e feijão-de-porco (Canavalia ensiformis) (FP), perfazendo um total de 6 tratamentos: T1 - Vegetação espontânea roçada+incorporada (VER+I); T2 - Vegetação espontânea roçada (VER); T3 - C. juncea roçada+incorporada (CJR+I); T4 - C. juncea roçada (CJR); T5 - Feijão-de-porco roçado+incorporado (FPR+I); T6 - Feijão-deporco roçado (FPR); com quatro repetições, totalizando 24 unidades experimentais.

Práticas como calagem e adubação mineral não foram realizadas nos seis anos anteriores. O preparo de solo para a semeadura das plantas de cobertura consistiu de uma aração (grade aradora de 78,74 pol.) à profundidade de 0,15-0,20 m e em seguida, duas gradagens (grade niveladora de 118,11 pol.) à profundidade de 0,10-0,12 m. Cada parcela experimental teve como área disponível $8,00 \mathrm{~m}^{2}(4,0 \mathrm{~m} \times 2,0 \mathrm{~m})$. $\mathrm{Na}$ semeadura, o sulcamento foi realizado manualmente e o espaçamento utilizado foi de $0,5 \mathrm{~m}$ entre linhas, totalizando 9 linhas de 2,0 $\mathrm{m}_{\text {linear }}^{-1} /$ tratamento.

As sementes de crotalária juncea e de feijão-de-porco utilizadas no semeio foram produzidas localmente, provenientes do banco de sementes de adubos verdes da Embrapa Meio-Norte, UEP ParnaíbaPI. Foi utilizada alta densidade de semeadura para a C. juncea $\left(25-30 \mathrm{~kg} \mathrm{ha}^{-1}\right)$ e de 80-100 kg ha-1 para o feijão de porco, ajustando-se posteriormente a população de plantas, por meio de desbaste aos vinte dias após a semeadura (20 DAS). A densidade de plantas foi ajustada para vinte e cinco plantas por metro linear para a crotalária juncea, e de cinco plantas por metro linear para o feijão-de-porco.

$\mathrm{Na}$ fase de manutenção, os tratos culturais para os adubos verdes foram realizados conforme o recomendado para as espécies (Teodoro, 2018), e para os tratamentos representados pela vegetação espontânea, não foram realizadas as capinas manuais.

Uma amostra, correspondendo a uma área útil de $0,5 \mathrm{~m}^{2}$, foi realizada para a identificação das plantas espontâneas. Para esta identificação foram realizados cortes com tesoura de poda rente ao solo, separadas e identificadas. Posteriormente, todo o material proveniente desta amostragem foi devolvido para os respectivos tratamentos no campo.

A vegetação espontânea presente nas parcelas experimentais foi identificada, sendo compostas principalmente por plantas da família das Poáceas. Sua ocorrência nas áreas provavelmente está associada à existência de banco de sementes de plantas espontâneas no solo ou de outra forma de dispersão (Tabela 2).

Tabela 2. Relação de espécies espontâneas ocorrentes em área experimental com a cultura da mandioca.

\begin{tabular}{lllc}
\hline Família & \multicolumn{1}{c}{ Nome científico } & Nome comum & Prevalência \% \\
\hline Amaranthaceae & Alternanthera tenella Colla. & Perpétua do campo & 5 \\
Asteraceae & Amaranthus deflexus L. & Caruru rasteiro & 5 \\
Commelinaceae & Emilia fosbergii Nicolson & Falsa serralha & 5 \\
Cyperaceae & Commelina benghalensis L. & Trapoeraba & 10 \\
Euphorbiaceae & Cyperus rotundus L. & Tiririca & $10^{*}$ \\
Fabaceae & Croton lobatus L. & Velame & 5 \\
& Indeterminada 1 & - & 5 \\
\hline
\end{tabular}


Ressalta-se o número elevado de espécies de vegetação espontânea do grupo $\mathrm{C}_{4}$ encontradas. Este grupo fisiológico representa as plantas com baixa taxa fotorrespiratória e, por conseguinte, maior capacidade fotossintética, agregada à alta eficiência no uso da água, nitrogênio e radiação, comparativamente às plantas $\mathrm{C}_{3}$, cultivadas em clima tropical (Long, 1999). Em função deste comportamento, poucas culturas são capazes de competir de forma eficiente com as plantas deste grupo.

Aos 60 dias de instalação do ensaio foram executados os cortes manuais definitivos para todos os tratamentos, inclusive para o tratamento testemunha (vegetação espontânea), quando mais de $50 \%$ dos adubos verdes (crotalária juncea e feijão de porco) atingiram o máximo florescimento (60-70 DAS). Toda biomassa foi depositada na superfície do solo correspondente ao tratamento.

Por ocasião dos cortes definitivos, uma amostra, correspondendo a uma área útil de $0,5 \mathrm{~m}^{2}$, foi realizada para a obtenção de leitura de biomassa seca das plantas de cobertura e da testemunha. $\mathrm{O}$ material proveniente da parte aérea foi colocado em sacos de papel e secos em estufa de ventilação forçada a $65^{\circ} \mathrm{C}$ por $48 \mathrm{~h}$ até atingir peso constante.

No preparo do solo para o plantio da mandioca, etapa posterior aos cortes definitivos para todos os tratamentos, foram utilizados dois sistemas: roçado com a deposição dos resíduos na superfície e roçado com a incorporação manual dos resíduos. Posteriormente, as parcelas foram novamente sulcadas e plantadas com a mandioca, não sendo utilizado qualquer tipo de adubação de plantio e cobertura.

O cultivo da mandioca, referente a dois ciclos (julho de 2014 a maio de 2015 e setembro de 2015 a junho de 2016, ambos os ciclos em pré-plantio com plantas de cobertura utilizadas como adubos verdes) foi realizado em fileiras simples, com espaçamento de 1,0 m x 0,5 m, em parcelas de $8,0 \mathrm{~m}^{2}$, utilizando-se manivas-semente de 0,15 $\mathrm{m}$ de comprimento, em posição horizontal e na profundidade de $0,1 \mathrm{~m}$.

As colheitas foram realizadas após 10 meses de plantio. Nas avaliações agronômicas, foram utilizadas como parcela útil, as três linhas centrais, totalizando área de 2,0 $\mathrm{m}^{2}$. Para a mandioca, foram avaliadas a produtividade comercial ( $\mathrm{PC}$ ), número de raízes por planta (NRP), massa média de raiz (MMR), diâmetro médio da haste (DMH), comprimento médio da raiz (CMR), massa de matéria verde de raízes (MVR), massa verde da parte aérea (MVPA), massa total (MT = MVR + MVPA), índice de colheita (IC), comprimento médio da haste $(\mathrm{CMH})$. Para as plantas de cobertura, incluindo a vegetação espontânea, foi avaliada a biomassa seca (BSPC).

Todo o material, tanto o proveniente da parte aérea como da raiz, foi pesado em balança de precisão. $\mathrm{O} \mathrm{DMH}$ foi avaliado com o auxílio de paquímetro, e para determinação do $\mathrm{CMH}$ foi utilizado fita métrica. Os dados foram anotados individualmente por planta e as médias foram calculadas por parcela.

Os resultados obtidos foram submetidos a análise de variância e comparadas pelo teste de Tukey para os casos em que houve diferença entre os manejos adotados, as plantas de cobertura utilizadas como adubos verdes, ou a interação entre eles, ao nível de significância de $5 \%$. O software utilizado para a análise estatística foi o Sisvar, versão 5.3 (Ferreira, 2011).

\section{Resultados e Discussão}

Não houve diferença ( $p>0.05)$ entre os tipos de manejo adotados e nem entre as coberturas utilizadas em pré-plantio nas avaliações agronômicas da mandioca: número de raízes por planta (NRP), massa média de raiz (MMR), diâmetro médio da haste (DMH), comprimento médio da raiz (CMR), massa de massa verde de raízes (MVR), massa verde da parte aérea (MVPA), massa total (MT = MVR + MVPA), índice de colheita $(\mathrm{IC})$, comprimento médio da haste $(\mathrm{CMH})$. Não houve diferença para a interação Manejo adotado x Adubos verdes. Também não houve diferenças $(p>0.05)$ entre os tratamentos nas avaliações agronômicas da mandioca para a produtividade comercial (PC) (Tabelas 3 e 4).

Tabela 3. Análise de variância de PC (t/ha) da cultura da mandioca sob coberturas vegetais utilizadas em préplantio como adubos verdes em um LATOSSOLO AMARELO Distrófico psamítico na região do litoral Piauiense.

\begin{tabular}{lccccc}
\hline \multicolumn{1}{c}{ Fonte da variação } & GL & SQ & QM & F & p-valor \\
\hline Manejo & 1 & 35,2837 & 35,2837 & 0,057 & 0,8135 \\
Adubos & 2 & 119,7758 & 59,8879 & 0,097 & 0,9078 \\
Manejo*Adubos & 2 & 769,6775 & 384,8337 & 0,625 & 0,5464
\end{tabular}


CV (\%): 37,73

* P-valor significativo menor que 0,05. Teste F.

Tabela 4. Produtividade comercial (t/ha) da cultura da mandioca sob coberturas vegetais utilizadas em préplantio como adubos verdes em um LATOSSOLO AMARELO Distrófico psamítico na região do litoral Piauiense.

\begin{tabular}{lccc}
\hline \multirow{2}{*}{ Manejo } & \multicolumn{3}{c}{ Adubos verdes } \\
\cline { 2 - 4 } & Vegetação espontânea & Crotalária juncea & Feijão de porco \\
\hline Roçada e incorporada & & & \\
Média & 67,93 & 53,66 & 71,96 \\
Desvio padrão & 15,78 & 26,77 & 23,29 \\
Mínimo & 56,00 & 19,80 & 56,40 \\
Máximo & 90,80 & 80,10 & 105,75 \\
Mediana & 62,45 & 57,38 & 62,85 \\
Roçada & & & \\
Média & 66,35 & 71,50 & 62,95 \\
Desvio padrão & 26,28 & 26,82 & 27,85 \\
Mínimo & 38,55 & 33,95 & 36,15 \\
Máximo & 94,75 & 97,55 & 100,50 \\
Mediana & 66,05 & 77,25 & 57,58 \\
\hline
\end{tabular}

Não houve interação entre o manejo do solo adotado e os adubos verdes, indicando que o tipo de manejo ( $R$ e $R+I$ ) independe dos tipos de coberturas utilizadas como adubos verdes (VE, CJ e FP). Nas avaliações por dois anos de safras (2014/15 e 2015/16), totalizando 26 meses, o uso de plantas para adubação verde em pré-plantio não influenciou na produtividade da mandioca. Entretanto, verificou-se que a média de PC (Tabela 3) obtida pelos tratamentos $\left(65,75 \mathrm{t} \mathrm{ha}^{-1}\right)$ foi superior à registrada para a cultura da mandioca no estado do Piauí, cuja média anual é de $9,65 \mathrm{t} \mathrm{ha}^{-1}$ (IBGE, 2019).

$\mathrm{O}$ uso de adubos verdes em sistemas agrícolas é fundamental à manutenção e melhoria da qualidade do solo, porém, para melhor aproveitar os inúmeros benefícios dessa tecnologia é preciso estabelecer estratégias que visem melhorar a sua eficiência na nutrição das culturas comerciais e na proteção do solo (Aita, Giacomini, Ceretta, 2014). Os mesmos autores condicionaram que a decomposição e a ciclagem de nutrientes resultantes desse processo esteja majoritariamente vinculada à atividade microbiana do solo para que haja eficácia. Por sua vez, Torres, Pereira, Loss, (2016), associaram a manutenção e deposição contínua de resíduos vegetais à melhoria do solo, sendo necessário para que esta melhoria ocorra, adoção do sistema conservacionista, por ao menos seis ou sete anos de adoção.

A não interação entre o manejo do solo adotado e os adubos verdes neste estudo pode ser corroborado por Araujo et al. (2019). Os referidos autores avaliaram, simultaneamente, na mesma área, a influência dos mesmos sistemas de manejo, nos atributos químicos e na atividade microbiana da área experimental, porém concluíram não haver diferenças relacionadas aos manejos adotados. Em condições análogas, Pinto et al. (2015) avaliaram a atividade microbiana de um Latossolo Amarelo sob adubação verde, também na UEP Parnaíba, e concluíram que a atividade metabólica da biomassa microbiana, expressa pela respiração basal, não foi influenciada pela adubação verde e manejos adotados, sendo estes de incorporação ou não da biomassa vegetal.

Portanto, o resultado obtido no presente trabalho para a cultura da mandioca pode estar associado ao fator tempo entre a deposição ou incorporação dos resíduos utilizados em pré-plantio, e o histórico de baixa atividade microbiana nas áreas da UEP.

Não foi observada diferença $(p>0.05)$ entre os manejos adotados em relação a biomassa seca das plantas de cobertura $(B S P C)$, porém observa-se diferenças $(p<0.05)$ entre as plantas utilizadas como adubos verdes em relação a biomassa seca (BSAV). Houve diferenças para a interação Manejo x Adubos, conforme pode ser observada na análise de variância realizada (Tabela 5). 
Tabela 5. Análise de variância da BSPC (t/ha) em pré-plantio à cultura da mandioca em um LATOSSOLO AMARELO Distrófico psamítico na região do litoral Piauiense.

\begin{tabular}{lccccc}
\hline \multicolumn{1}{c}{ Fonte da variação } & GL & SQ & QM & F & p-valor \\
\hline Manejo & 1 & 0,5643 & 0,5643 & 0,170 & 0,6852 \\
Adubos & 2 & 596,0425 & 298,0213 & 89,629 & $0,0000^{*}$ \\
Manejo*Adubos & 2 & 34,0629 & 17,0315 & 5,122 & $0,0173^{*}$ \\
Resíduo & 18 & 59,8510 & 3,3251 & & \\
Total corrigido & 23 & 690,5207 & & & \\
\hline CV $(\%): 15,32$ & & & &
\end{tabular}

CV (\%): 15,32

${ }^{*}$ P-valor significativo menor que 0,05 . Teste $\mathrm{F}$.

Como a análise de variância relativa à biomassa seca revelou efeito para os adubos verdes utilizados em pré-plantio, assim como para as interações manejos adotados $x$ adubos, utilizou-se o Teste de Tukey ao nível de $5 \%$ de significância para verificar as possíveis diferenças existentes (Tabela 6).

Tabela 6. Interação manejo adotado x adubos verdes utilizados em pré-plantio da mandioca em um LATOSSOLO AMARELO Distrófico psamítico na região no litoral Piauiense.

\begin{tabular}{lccc}
\hline \multirow{2}{*}{ Manejo } & \multicolumn{3}{c}{ Adubos verdes } \\
\cline { 2 - 4 } & Vegetação espontânea & Crotalária juncea & Feijão de porco \\
\hline Roçada e incorporada & $5,47 \mathrm{aA}$ & $17,24 \mathrm{aB}$ & $12,53 \mathrm{aC}$ \\
Roçada & $7,11 \mathrm{aA}$ & $19,26 \mathrm{aB}$ & $9,49 \mathrm{bA}$ \\
\hline
\end{tabular}

Letras minúsculas na vertical comparam o manejo dentro de Adubos Verdes. Letras maiúsculas na horizontal comparam os adubos verdes dentro do manejo. As médias seguidas de pelo menos uma mesma letra não difere entre si pelo teste de Tukey ao nível de $5 \%$ de probabilidade.

Constatou-se que a média de biomassa seca do feijão de porco foi a maior $(p<0.05)$, quando utilizado o manejo roçado e incorporado. Para as demais plantas utilizadas como adubos verdes (vegetação espontânea e Crotolária juncea) não houve diferença entre as médias de biomassa seca, independentemente do manejo adotado. Apesar disso, a Crotolária juncea se destaca frente às demais plantas por possuir as maiores médias de biomassa seca, independentemente do manejo adotado (somente roçada ou roçada e incorporada) (Tabela 6 ).

Cavalcante et al. (2012), estudando a produção de biomassa por plantas de cobertura no agreste Alagoano, obtiveram valores menores de biomassa seca de Crotalária juncea $\left(13,5 \mathrm{ha}^{-1}\right)$ e maiores para o feijão de porco $\left(16,2 \mathrm{t} \mathrm{ha}^{-1}\right)$, respectivamente, quando comparadas àquelas obtidas no presente estudo quanto ao manejo roçado (Tabela 6).

A produtividade de biomassa fresca e seca sob manejo roçado de sete espécies de leguminosas na região dos Tabuleiros Litorâneos do Piauí, dentre elas, a Crotalária juncea e o feijão-de-porco, foi avaliada por Teodoro, Castro, Magalhães, (2018). Segundo os autores, a biomassa seca da Crotalária juncea foi de 9,8 t ha-1, média inferior à obtida neste estudo $\left(19,26 \mathrm{t} \mathrm{ha}^{-1}\right)$ e a obtida por Teodoro, Santos, Lacerda, Araújo, (2016), que foi de 15,0 t ha-1. Quanto ao feijão de porco, Teodoro, Castro, Magalhães, (2018), obtiveram média de $14,55 \mathrm{t} \mathrm{ha}^{-1}$, sendo esta superior ao presente estudo $\left(9,49 \mathrm{t} \mathrm{ha}^{-1}\right)$.

Crotalária juncea e feijão de porco destacam-se na produção de biomassa seca como adubos verdes quando comparadas à vegetação espontânea. Ambas são superiores às observadas por Garcia (2002), em condições edafoclimáticas semelhantes à este estudo, com exceção da Crotalária juncea, provavelmente devido aos fatores climáticos observados no segundo semestre de 2015 , cuja média de precipitação no período foi de $24,0 \mathrm{~mm}$ (Figura 1). A vegetação espontânea obteve as menores médias de produção de biomassa seca $\left(5,5\right.$ a $7,1 \mathrm{t} \mathrm{ha}^{-1}$ ) (Tabela 6). Esse resultado é semelhante aos obtidos por Crusciol \& Soratto (2009); e Assis et al. (2016), que obtiveram médias variando de 2,0 a 7,2 $\mathrm{mg} \mathrm{ha}^{-1}$ (pousio).

As condições edáficas, climáticas e fitossanitárias, bem como, a época e o tipo de manejo, afetam a produção de biomassa, o acúmulo de nutrientes e o efeito da adubação verde sobre a cultura de interesse econômico (Amado, Mielniczuk, \& Aita, 2002, Dantas et al., 2015, Puiatti, Oliveira, Cecon, \& Bhering, 2015, Quaresma, Oliveira, \& Silva, 2017). De modo geral, devemos considerar que a eficiência de uma espécie recomendada para adubação verde depende de sua capacidade em produzir biomassa e reciclar nutrientes.

Nesse sentido, esses resultados reforçam o potencial de determinadas espécies para o uso como plantas de cobertura na adubação verde em solos arenosos, que apresentam baixos teores de matéria 
orgânica e baixa atividade microbiológica, como é o caso dos solos da região, onde o clima é caracterizado por altas temperaturas, longos períodos de seca e vento constante. Apesar disso, esses fatores estão incorporados ao processo produtivo da mandioca, e provavelmente explicam a baixa produtividade da cultura na região.

\section{Conclusões}

As coberturas vegetais, Crotalária juncea e feijão de porco, utilizadas em pré-plantio como adubos verdes em LATOSSOLO AMARELO Distrófico psamítico não influenciaram nas características agronômicas da mandioca na região do litoral Piauiesse.

A Crotalária juncea apresentou a maior produção de biomassa seca.

Recomenda-se a continuidade das avaliações, sobretudo avaliações de plantas de cobertura cuja dinâmica de decomposição dos resíduos culturais seja compatível com a proteção do solo (e estímulo aos microrganismos) e com o fornecimento de nutrientes que atenda a demanda da cultura da mandioca.

\section{Referências}

Aita, C., Giacomini, S.J., \& Ceretta, C.A. (2014). Decomposição e liberação de nutrientes dos resíduos culturais de adubos verdes. In: Lima Filho, O.F. de, Ambrosano, E.J., Rossi, F., Carlos, J.A.D. (Ed.). Adubação verde e plantas de cobertura no Brasil: fundamentos e prática. Brasília, DF: Embrapa, 1, p. 224264.

Alvares, C.A., Stape, J.L., Sentelhas, P.C., Alves, J.L.M.G., \& Sparovek, G. (2014). Köppen's climate classification map for Brazil. Meteorologische Zeitschrift, 22(6), p. 711-728.

Amado, T.J.C., Mielniczuk, J., \& Aita, C. (2002). Recomendação de adubação nitrogenada para o milho no RS e SC adaptada ao uso de culturas de cobertura no solo, sob sistema de plantio direto. Revista Brasileira de Ciência do Solo, 26(1), p. 241-248.

Araujo, F.S., Barroso, J.R., Freitas, L.O., Teodoro, M.S., Souza, Z.M., \& Torres, J.L.R. Chemical attributes and microbial activity of soil cultivated with cassava under different cover crops. (2019). Revista Brasileira de Engenharia Agrícola e Ambiental, 23(8), p. 614-619. https://doi.org/10.1590/1807-1929/agriambi.v23n8p614$\underline{619}$

Assis, R.L., Boer, C.A., Pacheco, L.P., Braz, A.J.B.P., Costa, K.A.P., \& Torres, J.L.R. (2016). Produção e decomposição de biomassa de plantas de cobertura cultivadas na primavera. Energia na Agricultura, 31, p. 328-333. https://doi.org/10.17224/EnergAgric.2016v31n4p328-333

Cardoso, R.A., Bento, A.S., Moreski, H.M., \& Gasparotto, F. Influência da adubação verde nas propriedades físicas e biológicas do solo e na produtividade da cultura de soja. (2014). Semina: Ciências Biológicas e da Saúde, Londrina, 35(2), p. 51-60. http://dx.doi.org/10.5433/1679-0367.2014v35n2p51

Cavalcante, V.S., Santos, V.R., Santos Neto, A.L., Santos, M.A.L., Santos, C.G., \& Costa, L.C. Biomassa e extração de nutrientes por plantas de cobertura. (2012). Revista Brasileira de Engenharia Agrícola e Ambiental, 16(5), p. 521-528. https://doi.org/10.1590/S1415-43662012000500008

Crusciol, C.A.C. \& Soratto, R.P. Nitrogen supply for cover crops and effects on peanut grown in succession under a no-till system. (2009). Agronomy Journal. Madison: American Society of Agronomy, 101, p. 41-46. http://dx.doi.org/10.2134/agroni2008.0054

Dantas, R.A., Carmona, R., Carvalho, A.M., Rein, T.A., Malaquias, J.V., \& Santos Júnior, J.D.G. (2015). Produção de matéria seca e controle de plantas daninhas por leguminosas consorciadas com cana-de-açúcar em cultivo orgânico. Pesquisa Agropecuária Brasileira, 50(8), p. 681-689.

Devide, A.C.P., Castro, C.M., Valle, T.L., Feltran, J.C., \& Almeida, J.C.R. Cultivo de mandioca de mesa em plantio direto e convencional sobre diferentes culturas de cobertura. (2017). Revista Brasileira de Energias Renováveis, 6, p. 274-285. DOI: 10.5380/rber.v6i2.48219 
FAO - Food and Agriculture Organization of the United Nations (2018). Agricultural production: crops primary. Disponível em: http://faostat.fao.org/. Acesso em: 05/11/2020.

Faria, C.M.B., Soares, J.M., \& Leão, P.C.S. Adubação verde com leguminosas em videira no submédio São Francisco. (2004). Revista Brasileira de Ciência do Solo, 28, p. 641-648. https://doi.org/10.1590/S010006832004000400006.

Ferreira, D.F. Sisvar: a computer statistical analysis system. (2011). Ciência e Agrotecnologia, Lavras, 35(6), p. 1039-1042.

Garcia, L.F. Introdução e avaliação de leguminosas para adubação verde em solos arenosos de Tabuleiros Costeiros do Piauí. (2002) Revista da Faculdade de Agronomia, Maracay, 28(2), p. 93-103.

Giongo, V., Salviano, A.M., Santana, M.S., Costa, N.D., \& Yuri, J.E. Soil management systems for sustainable melon cropping in the submedian of the são francisco Valley. (2016). Revista Caatinga, Mossoró, 29(3), p. 537-547. https://doi.org/10.1590/1983-21252016v29n303rc

Guareschi, R.F., Pereira, M.G., \& Perin, A. Adsorption of P and forms of iron in no-tillage areas in the 'Cerrado' biome. (2015). Acta Scientiarum. Agronomy, 37, p. 109-116. https://doi.org/10.4025/actasciagron.v37i1.17686

IBGE. Instituto Brasileiro de Geografia e Estatística. (2019). Sistema IBGE de recuperação automática, disponível em: http://www.sidra.ibge.gov.br

Long, S.P. (1999). Environmental responses. In: Sage, R.F., Monson, R.K. (Ed.). C4 plant biology. San Diego: Academic Press, p. 215-249.

Mehl, H.U., Sagrilo, E., Wolschick, D., \& Arzabe, C. (2010). Produção de biomassa e padrão de decomposição de adubos verdes cultivados nas entrelinhas de acerola orgânica. XII REUNIÃO BRASILEIRA DE MANEJO E CONSERVAÇÃO DO SOLO E DA ÁGUA, 18., 2010, Teresina. Anais... Teresina: CPAMN: UFPI, 4 p. 1 CD ROM.

Oliveira, K.J.B., Lima, J.S.S., Ambrósio, M.M.Q., Bezerra Neto, F., \& Chaves, A.P. Propriedades nutricionais e microbiológicas do solo influenciadas pela adubação verde. (2017). Revista de Ciências Agrárias, 40(1), p. 23-33. https://doi.org/10.19084/RCA16010

Pinto, T.C., Araújo, F.S., Freitas, L.O., Teodoro, M.S., Santos, V.B., \& Brito, A.C.C. Atividade microbiana de um latossolo amarelo sob adubação verde. XXXV Congresso Brasileiro de Ciência do Solo: o solo e suas múltiplas funções. Anais... Rio Grande do Norte, 2015.

Puiatti, M., Oliveira, N.L.C., Cecon, P.R., \& Bhering, A.S. (2015). Consorciação de taro e crotalária manejada com corte rente ao solo e poda na altura do dossel. Revista Ceres, 62(3), p. 275-283.

Quaresma, M.A.L., Oliveira, F.L., \& Silva, D.M.N. (2017). Leguminous cover crops for banana plantations in semi-arid regions. Revista Caatinga, 30(3), p. 614-621.

Raij, B. van, Andrade, J.C., Cantarella, H., \& Quaggio, J.A. (2001). Análise Química para Avaliação da Fertilidade de Solos Tropicais. Campinas, Instituto Agronômico, 285p.

Santos, H.G., Jacomine, P.K.T., Anjos, L.H.C., Oliveira, V.A., Lumbreras, J.F., Coelho, M.R., Almeida, J.A., Araujo Filho, J.C., Oliveira, J.B., \& Cunha, T.J.F. (2018). Sistema Brasileiro de Classificação de Solos. 5. ed. rev. e ampl. Brasília, DF: Embrapa, 356 p. E-book: il. color.

Teodoro, M.S., Santos, F.J.S, Lacerda, M.N., \& Araújo, L.M.S. Biomass yield of crotalaria juncea after thinning and at varied sowing densities in the coastal plateau of piauí state, brazil. (2016). Revista Caatinga, Mossoró, 29(4), p. 878 - 884. https://doi.org/10.1590/1983-21252016v29n412rc

Teodoro, M.S., Castro, K.N.C., \& Magalhães, J.A. Assessment of legumes with potential use as green manure in the coastal tablelands of piauí state, brazil. (2018). Revista Caatinga, Mossoró, 31(3), p. 584 - 592. https://doi.org/10.1590/1983-21252018v31n306rc

Teodoro, M.S. (2018). Adubação verde nos Tabuleiros Litorâneos do Piauí. Teresina: Embrapa Meio-Norte, 74 p. (Embrapa Meio-Norte. Documentos, 242). 
Torres, J.L.R., Pereira, M.G., \& Loss, A. (2016). Produção, decomposição e ciclagem de nutrientes das coberturas de solo utilizadas no sistema de semeadura direta no Cerrado. In: Amaral Sobrinho, N.M.B., Chagas, C.I., \& Zonta, E. (org.). Impactos ambientais provenientes da produção agrícola: Experiências argentinas e brasileiras. 1.ed. São Paulo/Rio de Janeiro: Livre Expressão, Cap.2, p.305-338. 